\title{
Lixiviação do Ametryn em ARgissolo Vermelho-Amarelo E Latossolo Vermelho-Amarelo, COM Diferentes ValoRes DE PH ${ }^{1}$
}

\author{
Ametryn Leaching on Red-Yellow Latosol and Red-Yellow Ultisol with Different pH Values
}

\author{
ANDRADE, S.R.B. ${ }^{2}$, SILVA, A.A. ${ }^{3}$, LIMA, C.F. ${ }^{4}$, D’ANTONINO, L. ${ }^{5}$, QUEIROZ, M.E.L.R. ${ }^{4}$, \\ FRANÇA, A.C. ${ }^{6} ;$ FELIPE, R.S. ${ }^{7}$ e VICTORIA FILHO, R. ${ }^{8}$
}

\begin{abstract}
RESUMO - Objetivou-se com este trabalho avaliar o potencial de lixiviação do ametryn num Argissolo Vermelho-Amarelo e num Latossolo Vermelho-Amarelo utilizados com pastagens no Brasil, com diferentes valores de $\mathrm{pH}$. Para isso, foram avaliados 120 tratamentos (quatro solos associados a três intensidades de chuva e 10 profundidades), em parcela subdividida no delineamento inteiramente casualizado, com três repetições. Colunas de PVC de $50 \mathrm{~cm}$ de comprimento por $10 \mathrm{~cm}$ de diâmetro foram preenchidas com os solos e umedecidas; em seguida, aplicou-se o herbicida e simularam-se chuvas no topo delas, nas intensidades especificadas de acordo com o tratamento. Após 72 horas, todas as colunas foram dispostas na posição horizontal e abertas longitudinalmente, coletando-se amostras dos solos a cada intervalo de $5 \mathrm{~cm}$ de profundidade, para posterior extração e quantificação do herbicida e análise por cromatografia liquida de alta eficiência - CLAE. Posteriormente, no restante das amostras de solo, semeou-se ao longo de cada coluna a espécie indicadora Cucumis sativus. Concluiu-se que solos com baixo teor de matéria orgânica e/ou pH mais elevado apresentaram maiores indices de lixiviação do ametryn. Além disso, o método do bioensaio foi mais eficiente na confirmação da lixiviação do ametryn em comparação à CLAE.
\end{abstract}

Palavras-chave: movimentação, herbicida, impacto ambiental, características do solo.

\begin{abstract}
The objective of this work was to evaluate ametryn leaching potential in soil used for pasture in Brazil (Red-Yellow Latosol (LVA) and Red-Yellow Ultisol (PVA)) with different pH values. Thus, 120 treatments were evaluated (four soils related to three rainfall intensities and 10 soil column depths). The experiments were arranged in a completely randomized design in split-plots and three replications. PVC columns of $10 \mathrm{~cm}$ diameter by $50 \mathrm{~cm}$ length were filled with the soil samples, moistened and placed upright for 48 hours to drain the excess water. The herbicide was applied and rainfall was simulated on top of the columns at intensities specified according to the treatment. After 72 hours, the columns were opened longitudinally, placed in a horizontal position and soil samples were collected at each $5 \mathrm{~cm}$ interval depth for posterior herbicide extraction and quantification by liquid chromatography (HPLC). The remaining soil columns were sown with the indicator species (Cucumis sativus) in the substrate along the opening to evaluate ametryn leaching. After 21 days of emergence, evaluations were conducted to verify the intoxication symptoms caused by ametryn in the plants. It was concluded that soils with low organic matter content and/or higher pH showed higher ametryn leaching rates, and that the bioassay method was more efficient in confirming ametryn leaching than liquid chromatography.
\end{abstract}

Keywords: movement, herbicide, environmental impact, soil characteristics.

1 Recebido para publicação em 10.8.2009 e na forma revisada em 3.9.2010.

2 Licenciada em Química, M.Sc., <shisleybarcelos@yahoo.com.br>; ${ }^{3}$ D.Sc., Professor Associado do Dep. de Fitotecnia,

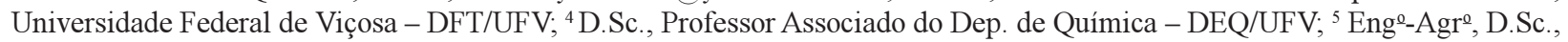
DFT/UFV; ${ }^{6}$ D.Sc., Professor Adjunto do Dep. de Agronomia, Universidade Federal dos Vales do Jequitinhonha e Mucuri UFVJM; 7 Graduando em Agronomia, UFV, Bolsista PIBIC/CNPq; ${ }^{8}$ Professor Titular, Dep. de Produção Vegetal, Escola Superior de Agricultura "Luiz de Queiroz - ESALQ/USP, <rvictoria@carpa.ciagri.usp.br>

Planta Daninha, Viçosa-MG, v. 28, n. 3, p. 655-663, 2010 


\section{INTRODUÇÃO}

Com a expansão do agronegócio, a utilização de herbicidas visando ao controle de plantas daninhas tornou-se ferramenta indispensável nos sistemas de produção agrícola, buscando aumentar a quantidade e a qualidade dos produtos ofertados com menor custo (Vivian et al., 2007; Arantes et al., 2006). Entre as diversas culturas de grande interesse econômico no Brasil, a cana-de-açúcar destaca-se, ocupando uma área de 6,0 milhões de hectares (CONAB, 2008). Por ser cultivada em larga escala e ter o crescimento inicial lento, a utilização do controle químico das plantas daninhas é ferramenta indispensável na condução da cultura da cana-de-açúcar, onde diversos herbicidas são aplicados anualmente (Southwick et al., 2002), entre eles o ametryn.

Segundo Rocha et al. (2003), a dinâmica e o destino dos herbicidas no ambiente são influenciados, principalmente, pela sorção às partículas do solo, a qual determina a disponibilidade de suas moléculas na solução do solo, ocorrendo, geralmente, relação inversa entre a sorção e o potencial de lixiviação desses compostos. Outros processos, assim como a dessorção, também influenciam o destino e o movimento dos herbicidas (Silva et al., 2007). $\mathrm{Na}$ solução do solo, as moléculas tendem a atingir equilíbrio entre a fase sorvida e a que permanece em solução. No entanto, a absorção pelas plantas, a eficácia e o transporte dependem em grande parte do equilíbrio entre os processos de sorção e dessorção. Geralmente, a eficiência e mobilidade dos herbicidas decrescem com o aumento da sua sorção pelos coloides do solo (Oliveira et al., 2005).

A retenção diferencial pode acarretar variabilidade no potencial de lixiviação do herbicida no perfil do solo (Oliveira Jr. et al., 2001). Portanto, existe a necessidade de monitoramento ambiental constante, assim como de desenvolvimento de diferentes métodos analíticos que visem à identificação, quantificação e elucidação do comportamento dos resíduos de herbicidas no solo. O uso incorreto e abusivo de herbicidas, a lixiviação e o escoamento superficial no solo estão entre os principais processos que contribuem para a contaminação de águas (Tanabe et al., 2001). No Estado de São Paulo, em regiões com intenso cultivo de cana-de-açucar, há relatos da contaminação de cursos d'água por ametryn, atrazine e simazine (Monteiro et al., 2008).

Entre os estudos realizados com águas superficiais e subterrâneas, o ametryn foi detectado em seis estados dos Estados Unidos em amostras de água superficial e em 4\% das amostras de águas subterrâneas (Extoxnet, 2007). Mitchell et al. (2005) identificaram resíduos de ametryn $\left(0,3 \mu \mathrm{g} \mathrm{L}^{-1}\right)$ e outros quatro herbicidas em águas de rios pertencentes à região de Mackay Whitsunday, na Austrália. Também Singh (2003) relata que vários estudos em lençóis aquiferos subterrâneos de regiões agrícolas dos Estados Unidos têm apresentado contaminações por herbicidas. Assim, objetivou-se com este trabalho avaliar o potencial de lixiviação do ametryn em um Argissolo Vermelho-Amarelo e em um Latossolo Vermelho-Amarelo, com diferentes valores de $\mathrm{pH}$.

\section{MATERIAL E MÉTODOS}

Amostras do Latossolo Vermelho-Amarelo (LVA) e do Argissolo Vermelho-Amarelo (PVA) foram coletadas em áreas isentas da aplicação de herbicidas, no município de Viçosa-MG, na profundidade de 0 a $20 \mathrm{~cm}$. As amostras do LVA foram divididas em três subamostras, sendo duas delas incubadas com diferentes quantidades de $\mathrm{CaCO}_{3}$ por 70 dias, com o intuito de obter amostras do solo com diferentes valores de $\mathrm{pH}$. Todas as amostras dos solos foram caracterizadas fisica e quimicamente (Tabela 1) após o período de incubação. Posteriormente, adicionou-se superfosfato simples às amostras na proporção de $1,0 \mathrm{~kg}$ por $100 \mathrm{~L}$ de solo, as quais foram a seguir homogeneizadas.

Após o preparo das amostras de solo, estas foram acondicionadas em colunas de PVC de $10,0 \mathrm{~cm}$ de diâmetro por $50,0 \mathrm{~cm}$ de comprimento. As colunas foram previamente preparadas e parafinadas interiormente, a fim de evitar escorrimento lateral interno da água a ser utilizada para promover a lixiviação do ametryn. Todas as colunas foram marcadas a cada $5 \mathrm{~cm}$ de distância no seu comprimento e possuíam tampa lateral removivel e uma estrutura vedante na base inferior, de tela de náilon, recoberta com papel-filtro, visando evitar perda de solo. Após o preenchimento das 
Tabela 1 - Caracterização física e química e classificação textural das amostras de solo utilizadas no experimento. Viçosa-MG

\begin{tabular}{|c|c|c|c|c|c|c|c|c|c|c|}
\hline \multicolumn{11}{|c|}{ Análise granulométrica } \\
\hline Solo & Argila & Silte & Areia fina & \multicolumn{2}{|c|}{ Areia grossa } & \multicolumn{5}{|c|}{ Classificação textural } \\
\hline LVA & 44 & 15 & 17 & \multicolumn{2}{|c|}{24} & \multicolumn{5}{|c|}{ Argiloso } \\
\hline PVA & 25 & 16 & 22 & \multicolumn{2}{|c|}{37} & \multicolumn{5}{|c|}{ Franco-Argilo arenoso } \\
\hline \multicolumn{11}{|c|}{ Análise química } \\
\hline \multirow{2}{*}{ Solo } & $\mathrm{pH}$ & $\mathrm{P}$ & $\mathrm{K}^{+}$ & $\mathrm{Ca}^{++}$ & $\mathrm{Mg}^{++}$ & $\mathrm{H}+\mathrm{Al}$ & $\begin{array}{l}\text { CTC } \\
\text { total }\end{array}$ & $\mathrm{V}$ & $\mathrm{m}$ & $\mathrm{MO}$ \\
\hline & $\left(\mathrm{H}_{2} \mathrm{O}\right)$ & \multicolumn{6}{|c|}{$\left(\mathrm{cmol}_{\mathrm{c}} \mathrm{dm}^{-3}\right)$} & \multicolumn{2}{|c|}{$(\%)$} & $\left(\right.$ dag kg $\left.^{-1}\right)$ \\
\hline LVA & 4,4 & 1,7 & 27 & 0,6 & 0,2 & 8,25 & 2,29 & 10 & 63 & 1,70 \\
\hline LVA & 4,9 & 1,7 & 27 & 1,0 & 0,4 & 7,26 & 2,37 & 15 & 44 & 1,70 \\
\hline LVA & 5,8 & 1,7 & 27 & 9,2 & 2,6 & 0,99 & 11,87 & 92 & 0 & 1,70 \\
\hline PVA & 5,9 & 5,2 & 81 & 2,8 & 1,4 & 2,64 & 4,47 & 63 & 0 & 2,55 \\
\hline
\end{tabular}

Análises realizadas no Laboratório de Análises de Solo Viçosa, segundo a metodologia da Empresa Brasileira de Pesquisa Agropecuária EMBRAPA (1997)

colunas com as amostras dos solos, procedeu-se ao umedecimento destes. Em seguida, as colunas foram deixadas em repouso por 72 horas na posição vertical, com intuito de drenar o excesso de água, até se atingir umidade equivalente próxima à capacidade de campo. Após essa etapa, fez-se a aplicação de $2.500 \mathrm{~g} \mathrm{ha}^{-1}$ de ametryn no topo das colunas, utilizando um pulverizador de precisão equipado com dois bicos TT 110.02 , espaçados de $0,50 \mathrm{~m}$, mantidos à pressão de 2,5 bar, aplicando-se o equivalente a 150,0 $\mathrm{L} \mathrm{ha}^{-1}$ de calda. Em seguida, as colunas foram encaminhadas à casa de vegetação do Departamento de Fitotecnia da Universidade Federal de Viçosa, onde foram mantidas durante todo o período experimental.

Vinte e quatro horas após a aplicação do herbicida, estando as colunas ainda na posição vertical, fez-se a simulação das chuvas de 20 , 40 e $80 \mathrm{~mm}$, de acordo com o tratamento específico. Depois disso, as colunas permaneceram ainda por 72 horas na posição vertical, sendo em seguida colocadas na posição horizontal. Nessa ocasião, foi feita a abertura lateral das colunas e realizada amostragem de solo a cada intervalo de $5,0 \mathrm{~cm}$ de profundidade, para posterior extração e quantificação do herbicida no solo por análise por cromatografia líquida CLAE. Posteriormente, foi feito na linha central das colunas um sulco de $1,0 \mathrm{~cm}$ de profundidade, onde se fez a semeadura do pepino (Cucumis sativus) como planta indicadora.
Foram avaliados 120 tratamentos: quatro solos (LVA pH 4,4; LVA pH 4,9; LVA pH 5,8; e PVA $\mathrm{pH} 5,9)$ associados a três intensidades de chuva $(20,40$ e $80 \mathrm{~mm})$ e 10 profundidades (0-5, 5-10, 10-15, 15-20, 20-25, 25-30, 30-35, 35-40, 40-45 e 45-50 cm), em esquema de parcelas subsubdivididas, no delineamento inteiramente casualizado, com três repetições.

Após a semeadura da espécie indicadora, manteve-se o solo das colunas com teor de umidade próximo a $80 \%$ da capacidade campo, por meio de irrigações diárias, para se garantir bom crescimento das plantas de pepino. A avaliação do índice de intoxicação das plantasteste pelo herbicida foi realizada aos 21 dias após a emergência destas, atribuindo-se notas de 0 (ausência de intoxicação) a 10 (morte da planta), de acordo com escala da EWRC (1964) modificada (Tabela 2).

Tabela 2 - Escala de sintomas de intoxicação provocados pelo ametryn em plantas de pepino (Cucumis sativus)

\begin{tabular}{|c|l|}
\hline Nota & \multicolumn{1}{|c|}{ Descrição dos sintomas } \\
\hline 0 & Ausência de intoxicação nas plantas \\
\hline 2 & $20 \%$ de intoxicação nas plantas \\
\hline 4 & $40 \%$ de intoxicação nas plantas \\
\hline 6 & $60 \%$ de intoxicação nas plantas \\
\hline 8 & $80 \%$ de intoxicação nas plantas \\
\hline 10 & Todas as plantas mortas \\
\hline
\end{tabular}

Fonte: escala EWRC (1964) modificada.

Planta Daninha, Viçosa-MG, v. 28, n. 3, p. 655-663, 2010 
Quanto à interpretação dos resultados, os dados obtidos foram submetidos a análise de variância, testes de médias e análises de regressão, adotando-se nível de significância de $5 \%$. Na escolha dos modelos, levaram-se em conta a resposta biológica e a significância do modelo.

Para extração do ametryn nas amostras de solo, foi utilizada a técnica de extração sólido-líquido, com partição em baixa temperatura, proposta por Vieira et al. (2007) e Goulart et al. (2008), com adaptações de tempo, pH e composição da solução extratora otimizadas por De Paula (2007).

A solução-estoque do ametryn foi preparada a partir do padrão, apresentando pureza de $98,3 \%$, solubilidade de $200,0 \mathrm{mg} \mathrm{L}^{-1}$ $\left(22^{\circ} \mathrm{C}\right)$, pKa de 4,1 e log Kow de 2,63, na concentração de $1.000 \mu \mathrm{g} \mathrm{mL}^{-1} \mathrm{em}$ acetonitrila, sendo as soluções de trabalho preparadas a partir da diluição desta. A partir da solução-estoque foram preparadas soluções de concentrações crescentes do herbicida em acetonitrila, para obtenção da curva de quantificação do ametryn (curva-padrão).

A fim de acompanhar a porcentagem de extração obtida a cada etapa do experimento, foram realizadas fortificações de amostras de solo. Adicionaram-se $100 \mu \mathrm{L}$ da solução-padrão do herbicida na concentração de $100,0 \mathrm{mg} \mathrm{L}^{-1}$ a 2,0 g de amostra de solo seco, obtendo-se uma concentração final de $5,0 \mathrm{mg} \mathrm{kg}^{-1}$. Depois da homogeneização da amostra, os frascos foram mantidos abertos, à sombra, para evaporação do excesso de acetonitrila. As amostras foram fortificadas por quatro horas para posterior extração, realizada juntamente com as amostras reais.

Utilizou-se metodologia otimizada, na qual se trabalhou com o mesmo herbicida e tipo de matriz de solo. Para confirmação dos resultados, foram realizados testes de extração e, em seguida, quantificação do extrato, em CLAE, usando as condições ótimas obtidas. Para isso, 2,0 g de amostra do solo previamente homogeneizado e quarteada foram colocados em frascos de vidro de tampa rosqueável com $22,0 \mathrm{~mL}$ de capacidade, adicionando-se a seguir 12,0 mL de uma mistura extratora, composta por 4,0 mL de água, $6,50 \mathrm{~mL}$ de acetonitrila e $1,50 \mathrm{~mL}$ de acetato de etila. Em seguida, esses frascos foram agitados sob 180 rotações por minuto (RPM) em mesa agitadora durante 30 minutos. Após isso, esses frascos foram deixados por \pm 12 horas em freezer na temperatura de aproximadamente $-20{ }^{\circ} \mathrm{C}$. Posteriormente, fez-se a filtragem das amostras em balão volumétrico de $10,0 \mathrm{~mL}$; apenas a fração não congelada (extrato orgânico mais herbicida) foi retirada por filtração comum. A fração que continha solo e água congelada foi descartada. Após atingir a temperatura ambiente, as soluções filtradas tiveram seu volume aferido a $10,0 \mathrm{~mL}$, sendo em seguida transferidas para balões de fundo redondo com 10,0 $\mathrm{mL}$ de capacidade, para serem concentradas em evaporador rotatório, à temperatura de $50 \pm 1{ }^{\circ} \mathrm{C}$. Em seguida, o balão de fundo redondo foi cuidadosamente lavado com três alíquotas de $0,50 \mathrm{~mL}$ de acetonitrila. Esse extrato final foi novamente filtrado em filtro Milipore de 0,45 $\mu \mathrm{m}$ e armazenado em microtubos de $1,50 \mathrm{~mL}$ de capacidade, para posterior análise por CLAE.

A validação do método ESL-PBT foi realizada considerando seletividade, linearidade, limite de detecção (LD), limite de quantificação (LQ), precisão e exatidão. Os principais parâmetros estão descritos na Tabela 3 , onde se verifica que os valores se encontram em conformidade com o descrito na literatura para a análise de pesticidas (Brito, 2003; INMETRO, 2003; Ribani et al., 2004), com média de recuperação entre 70 e $120 \%$ e CV < $20 \%$.

A análise cromatográfica foi realizada no Laboratório de Sintese de Agroquímicos (LASA) do Departamento de Química da UFV. O equipamento utilizado foi um cromatógrafo líquido de alta eficiência Shimadzu SPD2A. As condições de análise estão descritas na Tabela 1.

Tabela 3 - Principais parâmetros avaliados na validação do método de ESL-PBT com análise por CLAE

\begin{tabular}{|l|c|}
\hline Limite de detecção $\left(\mathrm{mg} \mathrm{L}^{-1}\right)$ & 0,01 \\
\hline Limite de quantificação $\left(\mathrm{mg} \mathrm{L}^{-1}\right)$ & 0,04 \\
\hline Percentual de recuperação $(\%)$ & 91,4 \\
\hline Coeficiente de variação (\%) & 3,8 \\
\hline Curva analítica & $\hat{\mathrm{Y}}=152393,9 \mathrm{x}+48,62$ \\
\hline Coeficiente de correlação $(\mathrm{r})$ & 0,999 \\
\hline
\end{tabular}


Para confirmar os resultados obtidos por CLAE, foram realizadas injeções de um padrão de $10 \mathrm{mg} \mathrm{L}^{-1}$ e de uma amostra aleatória em um cromatógrafo a gás acoplado a espectrômetro de massa (CG-MS) Shimadzu, modelo QP5050A. A coluna utilizada foi a DB5 com $30 \mathrm{~m}$ de comprimento, $0,25 \mathrm{~mm}$ de diâmetro interno e com filme de $0,25 \mu \mathrm{m}$ de espessura. As condições das análises cromatográficas estão descritas na Tabela 4.

Tabela 4 - Características dos métodos cromatográficos empregados na determinação por CLAE e por CG-MS para o ametryn

\begin{tabular}{|c|c|}
\hline \multicolumn{2}{|c|}{$\begin{array}{l}\text { Características cromatográficas do método de quantificação } \\
\text { do ametryn }\end{array}$} \\
\hline Fase estacionária & $\begin{array}{l}\text { Sílica-octadecil } \\
\text { (C18) }\end{array}$ \\
\hline \multicolumn{2}{|c|}{ CLAE } \\
\hline partícula $(\mathrm{m})$ & 5,0 \\
\hline Comprimento de onda $(\mathrm{nm})$ & 245 \\
\hline Comprimento da coluna (mm) & 250 \\
\hline interno da coluna & 4,0 \\
\hline Fase móvel & $\begin{array}{l}\mathrm{CH}_{3} \mathrm{CN}: \mathrm{H}_{2} \mathrm{O}\left(\mathrm{H}_{3} \mathrm{PO}_{4}\right) \\
48: 52+0,1 \%\end{array}$ \\
\hline Vazão $\left(\mathrm{mL} \mathrm{min}^{-1}\right)$ & 1,2 \\
\hline Volume de injeção ( $\mathrm{L}$ ) & 20 \\
\hline Tempo de retenção (min) & 13 \\
\hline \multicolumn{2}{|c|}{ CG-MS } \\
\hline Coluna & DB5 \\
\hline Comprimento da coluna (m) & 30 \\
\hline coluna $(\mathrm{mm})$ & 0,25 \\
\hline filme ( $\mathrm{m})$ & 0,25 \\
\hline Temperatura de injeção ( C) & 290,0 \\
\hline Temperatura do detector ( $\mathrm{C}$ ) & 290,0 \\
\hline Fluxo da coluna $\left(\mathrm{mL} \mathrm{min}^{-1}\right)$ & 1,6 \\
\hline $\begin{array}{l}\text { Programação da temperatura da } \\
\text { coluna ( C) }\end{array}$ & $\begin{array}{c}80 \mathrm{C} \text { por } 5 \mathrm{~min} . \\
\text { Aumentando a cada } 4 \mathrm{~min} \\
\text { até atingir } 285 \mathrm{C}\end{array}$ \\
\hline Tempo de retenção (min) & 34,7 \\
\hline Faixa de relação massa/carga $(\mathrm{m} / \mathrm{z})$ & $30,0-700,0$ \\
\hline Volume de injeção ( $\mathrm{L}$ ) & 1,0 \\
\hline Razão de split & $: 1$ \\
\hline
\end{tabular}

\section{RESULTADOS E DISCUSSÃO}

Quanto à lixiviação do ametryn nas colunas de solo, verifica-se que ela foi influenciada pela intensidade de chuva, pelas características físicas e químicas e pelo teor de matéria orgânica dos solos (Figura 1). No Latossolo
Vermelho-Amarelo, pH 4,4, observou-se intoxicação de $100 \%$ das plantas de pepino, independentemente da intensidade da chuva simulada, até a profundidade de $10 \mathrm{~cm}$. Quando se compara a lixiviação do herbicida neste mesmo solo nos diferentes valores de $\mathrm{pH}(4,4$, 4,9 e 5,8), fica evidente que no solo com maiores valores de $\mathrm{pH}$ o ametryn foi mais lixiviado. Nessa condição, o herbicida causou elevado indice de intoxicação, que foi influenciado pelo volume de chuva, em todas as plantas ao longo das colunas, evidenciando a percolação do herbicida até a profundidade de $50 \mathrm{~cm}$ (profundidade máxima da coluna). Segundo Ferri et al. (2000), em condições de baixo pH do solo, próximo ao valor de pKa de herbicidas básicos, como o ametryn, pode ocorrer a protonação de suas moléculas, adquirindo assim cargas positivas. Essas cargas terão grande possibilidade de ser adsorvidas pelos coloides do solo, que apresentam predominantemente cargas negativas (Lindsay, 2001). No caso do Latossolo Vermelho-Amarelo, com baixo teor de matéria orgânica, fica mais evidente a influência do $\mathrm{pH}$ do solo na distribuição das cargas, pois estas, em sua maioria, são dependentes de $\mathrm{pH}$ (Lindsay, 2001). Isso confirma a menor sorção e, consequentemente, maior lixiviação nas colunas do LVA com maiores valores de $\mathrm{pH}$, mantendo-se as suas características fisicas e o teor de matéria orgânica.

Também Hartzler et al. (1989) verificaram que o $\mathrm{pH}$ altera a disponibilidade de herbicidas na solução do solo. Comparando os gráficos da Figura 1, que representam a porcentagem de intoxicação das plantas de pepino pelo ametryn após submetido à lixiviação por diferentes volumes de chuva (20,40 e $80 \mathrm{~mm}$ ) e que têm as equações de regressão descritas na Tabela 4, verifica-se que para solos diferentes com valores próximos de $\mathrm{pH}$ (LVA pH 5,8 e PVA pH 5,9) ocorreu movimentação diferenciada do ametryn, a qual foi também influenciada pelo volume de chuva (maior volume de chuva e maior lixiviação para um mesmo solo, no mesmo valor de $\mathrm{pH}$ ). Nas amostras do LVA que apresenta maior teor de argila, porém menor teor de matéria orgânica em relação ao PVA (Tabela 1), verificou-se maior intensidade dos sintomas de intoxicação das plantas pelo herbicida ao longo de toda a coluna. Isso pode ter ocorrido devido à distribuição mais uniforme do ametryn ao longo da coluna, 


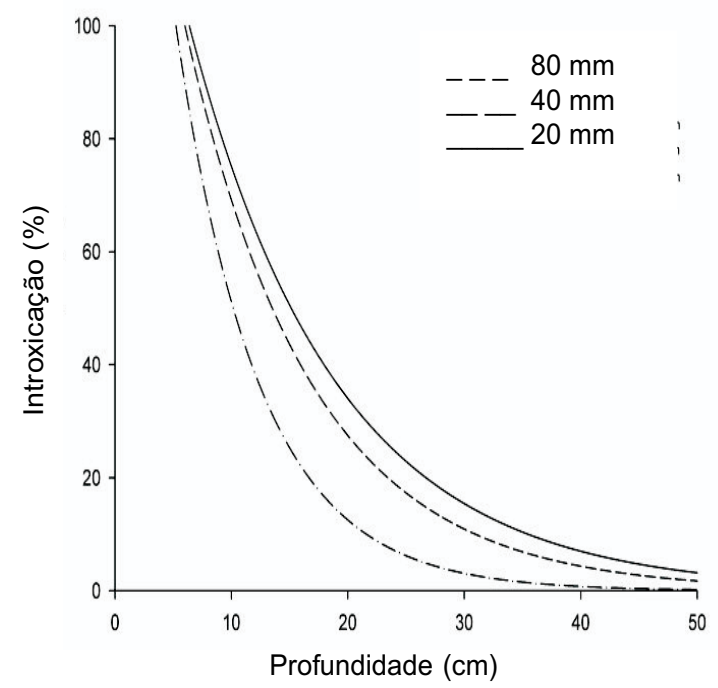

Solo LVA - pH 4,4

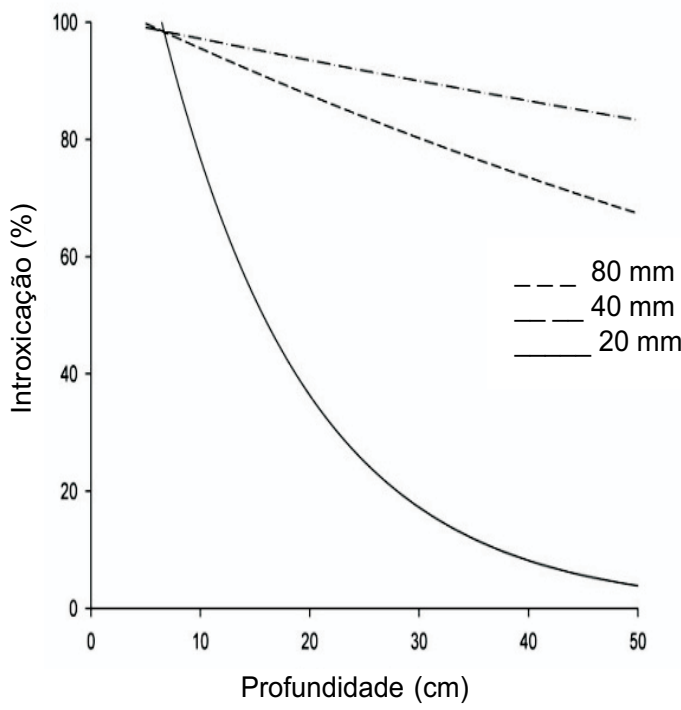

Solo LVA - pH 5,8

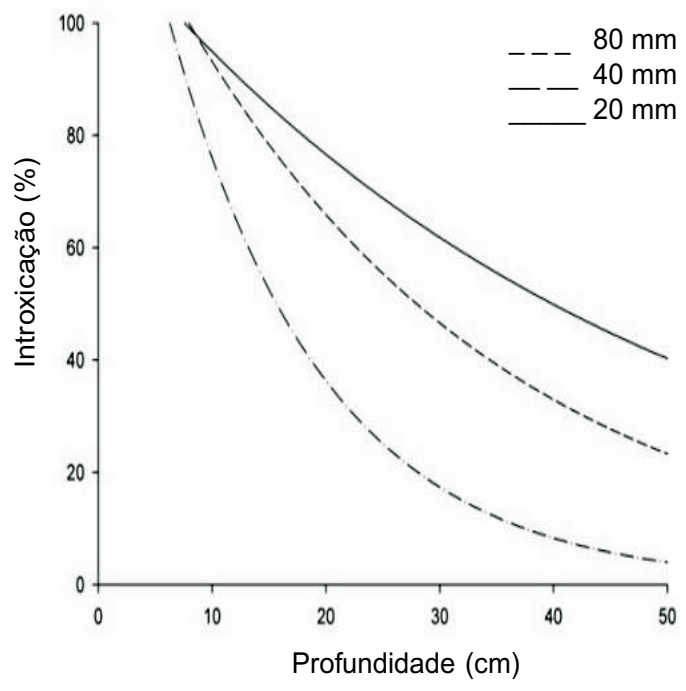

Solo LVA - pH 4,9

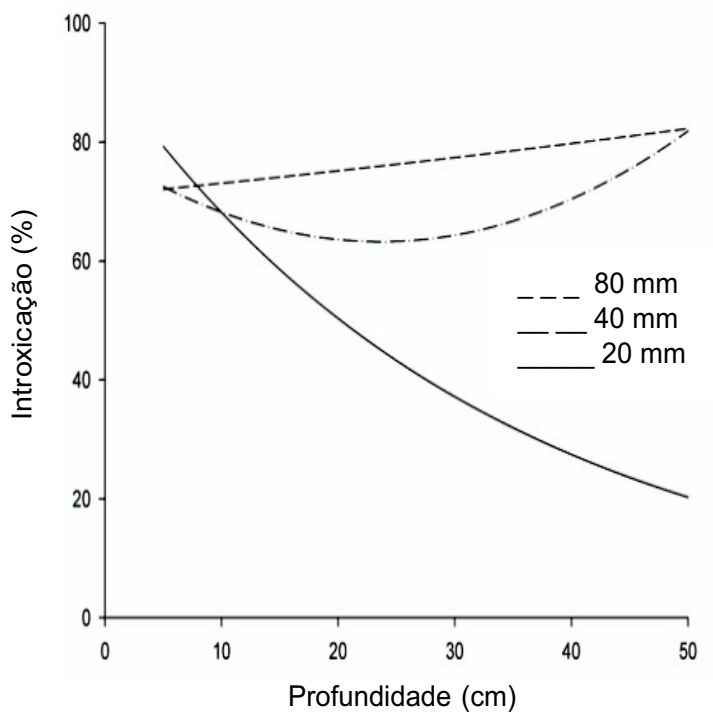

Solo PVA - pH 5,9

Figura 1 - Porcentagem de intoxicação de plantas de pepino cultivadas em amostras de Latossolo Vermelho-Amarelo ( $\mathrm{pH} 4,4,4,9$ e 5,9) e em Argissolo Vermelho-Amarelo ( $\mathrm{pH}$ 5,9), em função de diferentes profundidades das colunas, após a aplicação de ametryn e simulação de chuvas de 20, 40 e 80 mm. Viçosa-MG. 2007.

confirmando a maior mobilidade do herbicida. Esses resultados estão de acordo com os de Vivian et al. (2007) e Tavares et al. (2005), os quais relatam que maiores teores de matéria orgânica no solo fazem com que o ametryn, que é uma base fraca, tenha suas moléculas atraídas eletrostaticamente pelos grupos carboxílicos, fenólicos, entre outros da matéria orgânica, deixando-o, assim, menos disponivel na solução do solo.
Ao comparar os resultados obtidos no bioensaio com os obtidos em CLAE (Tabela 5), verifica-se que nas regiões das colunas onde se quantificou concentração de herbicida igual ou superior a $0,04 \mathrm{mg} \mathrm{L}^{-1}$ (LQ do equipamento) ocorreram altas porcentagens de intoxicação nas plantas. No entanto, em algumas regiões das colunas (profundidades), onde as plantas indicadoras apresentaram sintomas de intoxicação pelo ametryn fracos 
Tabela 5 - Equações de regressão e coeficientes de determinação da intoxicação em plantas de pepino cultivadas em solo em função das profundidades das colunas, preenchidas com amostras de Argissolo Vermelho-Amarelo (pH 5,9) e Latossolo VermelhoAmarelo ( $\mathrm{pH} 4,4,4,9$ e 5,8), tratadas com ametryn e submetidas a chuvas de 20, 40 e $80 \mathrm{~mm}$. Viçosa-MG, 2007

\begin{tabular}{|c|c|c|c|}
\hline Solo & Volume de chuva & Equação & $\overline{\mathrm{R}^{2}}$ \\
\hline \multirow{3}{*}{ LVA pH 4,4 } & 20 & $\hat{\mathrm{Y}}=165,9949^{-0,0792 x}$ & 0,91 \\
\hline & 40 & $\hat{\mathrm{Y}}=170,5367^{-0,0892 x}$ & 0,93 \\
\hline & 80 & $\hat{\mathrm{Y}}=209,3223^{-0,1409 x}$ & 0,97 \\
\hline \multirow{3}{*}{ LVA pH 4,9 } & 20 & $\hat{\mathrm{Y}}=128,8836^{-0,0327 x}$ & 0,96 \\
\hline & 40 & $\hat{\mathrm{Y}}=131,7494^{-0,0347 x}$ & 0,93 \\
\hline & 80 & $\hat{\mathrm{Y}}=158,9121^{-0,0738 \mathrm{x}}$ & 0,95 \\
\hline \multirow{3}{*}{ LVA pH 5,8 } & 20 & $\hat{\mathrm{Y}}=162,2263^{0,0748 x}$ & 0,95 \\
\hline & 40 & $\hat{\mathrm{Y}}=104,2626^{-0,0087 x}$ & 0,89 \\
\hline & 80 & $\hat{\mathrm{Y}}=101,0107^{-0,0039 x}$ & 0,88 \\
\hline \multirow{3}{*}{ LVA pH 5,9 } & 20 & $\hat{\mathrm{Y}}=-92,3684^{-0,0303 x}$ & 0,92 \\
\hline & 40 & $\hat{\mathrm{Y}}=71,0914^{-368,2301}$ & 0,81 \\
\hline & 80 & $\hat{\mathrm{Y}}=78,1667-1,2641 \mathrm{x}+0,0268 \mathrm{x}^{2}$ & 0,84 \\
\hline
\end{tabular}

e moderados, não foi possivel quantificar o herbicida por cromatografia. Provavelmente, o herbicida se encontrava com concentração abaixo do limite de detecção do equipamento $\left(0,01 \mathrm{mg} \mathrm{L}^{-1}\right)$. Esse fato pode ser atribuído a um possivel problema na amostragem, que foi feita sem retirada total do solo. Sugere-se, portanto, que para esse tipo de quantificação seja feita uma coluna-teste para cada ensaio, com a finalidade especifica de se retirar todo o solo e conduzi-lo ao laboratório para a ESL-PBT, e posterior quantificação por CLAE, fazendo, dessa forma, o plantio da planta indicadora em outra coluna. Os resultados obtidos no bioensaio sugerem que a técnica pode ser muito útil na confirmação do potencial de lixiviação desse herbicida em colunas de solo.

Foi observado que o solo com maior teor de matéria orgânica, PVA, apresentou menor lixiviação do ametryn que o LVA, apesar de este solo apresentar maior teor de argila (Figura 1). Dependendo do herbicida e das características físicas e químicas do solo, a fração argila, ou a orgânica, pode ser a mais importante. Segundo Silva et al. (2007), em diversos casos não há correlações entre a sorção do herbicida e as concentrações de argila. Isso ocorre porque as características
Tabela 6 - Concentração do ametryn, determinada por cromatografia - CLAE, em amostras de solo coletadas em diferentes profundidades das colunas, após simulação de chuvas

\begin{tabular}{|l|c|c|c|c|}
\hline \multirow{3}{*}{ Solo } & \multicolumn{4}{|c|}{ Profundidade de coleta (cm) nas colunas com 20 } \\
\cline { 2 - 5 } & $0-5$ & $5-10$ & $10-15$ & $15-50$ \\
\cline { 2 - 5 } & \multicolumn{5}{|c|}{ Concentração $\left(\mathrm{mg} \mathrm{kg}^{-1}\right)$} \\
\hline LVA 4,4 & 0,17804 & 0,02575 & 0 & 0 \\
\hline LVA 4,9 & 0,06038 & 0,04501 & 0 & 0 \\
\hline LVA 5,8 & 0,37865 & 0,08582 & 0,06360 & 0 \\
\hline PVA 5,9 & 0,86456 & 0 & 0 & 0 \\
\hline \multirow{3}{*}{ Solo } & Profundidade de coleta (cm) nas colunas com \\
\cline { 2 - 5 } & $0-5$ & $5-10$ & $10-15$ & $15-50$ \\
\cline { 2 - 5 } & \multicolumn{5}{|c|}{ Concentração (mg kg $\left.{ }^{-1}\right)$} \\
\hline LVA 4,4 & 1,17632 & 0,42022 & 0,15456 & 0 \\
\hline LVA 4,9 & 0,11040 & 0,06248 & 0,04898 & 0 \\
\hline LVA 5,8 & 0,43643 & 0,13617 & 0 & 0 \\
\hline PVA 5,9 & 0,66054 & 0 & 0 & 0 \\
\hline \multirow{3}{*}{ Solo } & Profundidade de coleta (cm) nas colunas com \\
\cline { 2 - 5 } & $0-5$ & $5-10$ & $10-15$ & $15-50$ \\
\cline { 2 - 5 } & \multicolumn{5}{|c|}{ Concentração (mg kg $\left.{ }^{-1}\right)$} \\
\hline LVA 4,4 & 0,26936 & 0,23445 & 0 & 0 \\
\hline LVA 4,9 & 0,67437 & 0,13015 & 0,09642 & 0 \\
\hline LVA 5,8 & 1,02075 & 0,03638 & 0 & 0 \\
\hline PVA 5,9 & 0,44471 & 0 & 0 & 0 \\
\hline
\end{tabular}


químicas das argilas dependem do material de origem do solo e do grau de intemperismo deste, o que varia muito em condições tropicais (Lindsay, 2001). Todavia, nos herbicidas de caráter básico ou não iônicos, é comum a correlação da sorção com o teor de matéria orgânica do solo (Oliveira Junior et al., 2001). Desse modo, a matéria orgânica nos solos estudados pode ter tido efeito mais pronunciado na sorção do ametryn, ao contrário da fração argila. Esses resultados estão de acordo com a teoria proposta por Brusseau \& Rao (1989) e com os relatos de Vieira et al. (1999) e Vivian et al. (2007).

Conclui-se que a lixiviação do ametryn foi influenciada pela intensidade de chuva, pelo teor de matéria orgânica e pelo $\mathrm{pH}$ dos solos. Em um mesmo solo (LVA) com maiores valores de $\mathrm{pH}$ e de chuva simulada, ocorreu maior lixiviação do herbicida. A lixiviação do ametryn em solos com valores próximos de $\mathrm{pH}$ (LVA $\mathrm{pH} 5,8$ e PVA-pH 5,9) foi menor no solo com maior teor de matéria orgânica (PVA-pH 5,9), quando comparado ao solo com menor teor (LVA-pH 5,8).

\section{LITERATURA CITADA}

ARANTES, S. A. C. M. et al. Sorção da atrazina em solos representativos da sub-bacia do Rio dos Montes-MG.

Pesticidas: R. Ecotoxicol. Meio Amb., v. 16, p. 101-110, 2006.

BRITO, N. M. et al. Validação de métodos analíticos: estratégia e discussão. Pesticidas: R. Ecotoxicol. Meio Amb., v. 13 p. 129-146, jan/dez., 2003.

BRUSSEAU, M. L.; RAO, P. S. C. The influence of sorbateorganic matter interactions on sorption nonequilibrium. Chemosphere, v. 18, n. 9/10, p. 1691-1706, 1989.

COMPANHIA NACIONAL DE ABASTECIMENTO CONAB. Levantamento sistemático da produção agrícola Disponível em: $<$ http://www.conab.gov.br>. Acesso em: 10 ago. 2008

DE PAULA, R. T. Mobilidade de atrazine e ametryn em Latossolo Vermelho-Amarelo. 2007. 105 f. Dissertação (Mestrado em Agroquímica) - Universidade Federal de Viçosa, Viçosa, MG, 2007.

EMPRESA BRASILEIRA DE PESQUISA AGROPECUÁRIA - EMBRAPA. Centro Nacional de Pesquisa de Solos. Manual de métodos de análise de solos. 2.ed. Rio de Janeiro: 1997. 212 p.

Planta Daninha, Viçosa-MG, v. 28, n. 3, p. 655-663, 2010
EXTENSION TOXICOLOGY NETWORK - EXTOXNET. Pesticides information profiles. Disponível em: $<\mathrm{http} / / /$ www.extoxnet.orst.edu/pips/ametryn.htm>. Acesso em: 15 maio 2007

EUROPEAN WEED RESEARCH COUNCIL - EWRC Report of the $3^{\text {rd }}$ and $4^{\text {th }}$ meetings of EWRC - Comittee of Methods in Weed Research. Weed Res., v. 4, n. 1, p. 88, 1964.

FERRI, M. V. W. et al. Atividade dos herbicidas flumetsulam e trifluralin em diferentes valores de $\mathrm{pH}$ e densidade do solo. Ci. Rural, v. 30, n. 1, p. 11-15, 2000

GOULART, S. M. et al. Low-temperature clean-up method for the determination of pyrethroids in milk using gas chromatography with electron capture detection. Talanta, v. 75 , p. 1320-1323, 2008.

HARTZLER, R. G. et al. Effects of tillage on trifluralin residue carryover injury to corn (Zea mays). Weed Sci., v. 37, n. 4, p. 609-615, 1989.

INSTITUTO NACIONAL DE METROLOGIA, NORMALIZAÇÃO E QUALIDADE INDUSTRIAL INMETRO. Orientações sobre validação de métodos de ensaios químicos - DOQ-CGCRE-008. Março, 2003

LINDSAY, W. L. Chemical equilibria in soils. New Jersey: Blackburn, 2001. 449 p

MITCHELL, C. et al. Sedments, nutrients and pesticide residues in event flow conditions in strams of the Mackaay Whitsunday region, Austrália. Marine Poll. B., v. 51, n. 1, p. 23-36, 2005

MONTEIRO, R. T. R. et al. Projeto Políticas Públicas. In: TAUK-TORNISIELO, S. M.; ESQUIERRO, J. C. (Org.). Bacia do Rio Corumbataí: aspectos socioeconômicos e ambientais. Rio Claro: Universidade Estadual de São Paulo, 2008. p. 5-178.

OLIVEIRA Jr., R. S.; KOSKINEN, W. C.; FERREIRA, F. A. Sorption and leaching potential of herbicides in Brazilian soils. Weed Res., v. 41, p. 97-110, 2001

OLIVEIRA, M. F.; PRATES, H. T.; SANS, L. M. A. Sorção e hidrólise do herbicida flazasulfuron. Planta Daninha, v 23, n. 1, p. 101-113, 2005.

RIBANI, M. et al. Validação em métodos cromatográficos e eletroforéticos. Química Nova, v. 27, n. 5, p. 771-780, 2004.

ROCHA, W. S. D., ALLEONI, L. R. F.; REGITANO, J. B. Energia livre da sorção de imazaquin em solos ácricos. R. Bras. Ci. Solo, v. 27, n. 2, p. 239-246, 2003. 
SILVA, A. A. et al. Herbicidas: comportamento no solo. In SILVA, A. A.; SILVA, J. F. (Ed.). Tópicos em manejo de plantas daninhas. Viçosa, MG: Universidade Federal de Viçosa, 2007. p. 189-248.

SINGH, N. Organic manure and urea effect on metolachlor transport through packed soil columns. J. Environ. Quality, v. 32, p. 1743-1749, 2003.

SOUTHWICK, L. M. et al. Potential influence of sugarcane cultivation on estuarine water quality of Louisiana's gulf coast. J. Agric. Food Chem., v. 50, n. 15, p. 4393-4399, 2002.

TANABE, A. et al. Seasonal and special studies on pesticides residues in surface eaters of the Shinano river in Japan. $\mathbf{J}$. Agric. Food Chem., v. 49, n. 6, p. 3847-3852, 2001.
TAVARES, A. et al. Determinação of ametryn in soils via microwave-assisted solvent extraction coupled to anodic stripping voltammetry with a gold ultramicroelectrode. Anal. Bional. Chem., v. 382, n. 2, p. 477-484, 2005.

VIEIRA, H. P. et al. Otimização e validação da técnica de extração líquido-líquido com partição em baixa temperatura (ELL-PBT) para piretróides em água e análise por CG. Quimica Nova, v. 30, n. 3, p. 535-540, 2007.

VIEIRA, E. M. et al. Estudo da sorção/dessorção do ácido 2,4 diclorofenoxiacético (2,4-D) em solo na ausência e presença de matéria orgânica. Química Nova, v. 22, n. 3, p. 305-308, 1999.

VIVIAN, R. et al. Persistência e lixiviação de ametryn e trifloxysulfuron-sodium, em solo cultivado com cana-deaçúcar. Planta Daninha, v. 25, n. 1, p. 111-124, 2007. 